\title{
Фотоэдс на поверхности сильнолегированного $p$-GaAs с адсорбированными слоями цезия и кислорода
}

\author{
В.С. Хорошилов ${ }^{1,2}$, Д.Е. Протопопов ${ }^{1,2}$, Д.М. Казанцев ${ }^{1,2}$, А.Г. Журавлев ${ }^{1,2}$, В.Л. Альперович ${ }^{1,2}$ \\ ${ }^{1}$ Институт физики полупроводников им. А.В.Ржанова СО РАН, 630090, Новосибирск \\ ${ }^{2}$ Новосибирский государственный университет, 630090, Новосибирск \\ тел:+7 (383)330-98-74, эл.nочта: alper@isp.nsc.ru
}

DOI 10.34077/RCSP2021-133

Уменьшение изгиба зон из-за поверхностной фотоэдс лежит в основе работы фотоприемников на барьерах Шоттки и влияет на работу $p^{+}-\mathrm{GaAs}(\mathrm{Cs}, \mathrm{O})$-фотокатодов с отрицательным электронным сродством (ОЭС). Ранее фотоэдс на поверхности $p$ - $\mathrm{GaAs}(\mathrm{Cs}, \mathrm{O})$ изучалась бесконтактным методом фотоотражения на $\mathrm{UP}^{+}$-структурах с тонким ( $\approx 100$ нм) нелегированным слоем [1] и на образцах с умеренным уровнем легирования $p \approx 3 \times 10^{17} \mathrm{~cm}^{-3}[2]$. При больших концентрациях дырок, определение фотоэдс этим методом затруднено из-за малой величины сигнала фотоотражения.

В данной работе разработана методика измерения поверхностной фотоэдс в сильнолегированном $\mathrm{GaAs}$, основанная на влиянии изгиба зон на эффективное электронное сродство и, как следствие, на квантовый выход фотоэмиссии из полупроводника в вакуум [3]. В этой методике поверхность полупроводника освещается двумя пучками света с одинаковой длиной волны, интенсивности которых модулированы на различных частотах $f_{1}$ и $f_{2}$. Каждый пучок света генерирует поверхностную фотоэдс и ток фотоэмиссии из образца. Изменение тока эмиссии от одного пучка, вызванное поверхностной фотоэдс от другого пучка, приводит к появлению суммарной и разностной гармоник $f_{1} \pm f_{2}$ в этом токе. В данной работе амплитуды этих гармоник измеряются путём последовательного синхронного детектирования частот $f_{1}$ и $f_{2}$. При этом «перекрестные» вклады от влияния первого пучка на второй и второго на первый предполагаются одинаковыми. Это позволяет определить абсолютные значения фотоэдс с использованием экспоненциальной зависимости тока фотонно-усиленной термоэлектронной эмиссии от эффективного электронного сродства [4].

С помощью предложенной методики экспериментально изучена эволюция фотоэдс при адсорбции слоёв цезия и кислорода на поверхности сильнолегированного $p^{+}$-GaAs c актуальным для ОЭСфотокатодов уровнем легирования $p \approx 7 \times 10^{18} \mathrm{~cm}^{-3}$. При нанесении цезия на чистую поверхность $p^{+}$$\mathrm{GaAs}$, в области Cs покрытий $\theta>0.3 \mathrm{ML}$ обнаружен монотонный спад поверхностной фотоэдс. Аналогичный спад фотоэдс наблюдался ранее на UP+-структурах и на образцах $p$-GaAs c умеренным уровнем легирования. Предположительно, спад фотоэдс связан с формированием двумерных металлических кластеров цезия, приводящим к росту локальной поверхностной проводимости и скорости поверхностной рекомбинации.

При активировании поверхности $p^{+}$-GaAs цезием и кислородом до состояния с ОЭС обнаружены «переключения» между большой фотоэдс после нанесения слоев кислорода и малой фотоэдс после нанесения слоев цезия. Ранее на $\mathrm{UP}^{+}$-структурах и умеренно легированных образцах наблюдалась обратная картина с большими значениями фотоэдс после нанесения цезия, что объяснялось Сsиндуцированным увеличением изгиба зон. Выявленное различие свидетельствует о доминирующем влиянии на фотоэдс изменений скорости поверхностной рекомбинации на поверхности $p^{+}$-GaAs. Уменьшение скорости поверхностной рекомбинации при нанесении кислорода обусловлено, предположительно, разрушением цезиевых кластеров. Эта гипотеза согласуется с наблюдавшимися нами в данной работе $\mathrm{Cs}-\mathrm{O}$ переключениями интенсивности фотолюминесценции.

Работа выполнена при финансовой поддержке РФФИ, грант № 20-02-00355.

\section{Лuтература}

[1] V.L. Alperovich et al. // Appl. Phys. Lett. 1995. V.66 P.2122.

[2] V.L. Alperovich et al. // Phys. Rev. B. 1994. V.50. P.5480.

[3] V.S. Khoroshilov et al. // J. Phys. Conf. Ser. 2020. V.1482. P.012013.

[4] A.G. Zhuravlev et al. // Appl. Phys. Lett. 2014. V.105 P.251602. 